\title{
Long-term bonding efficacy of adhesives containing benzodioxioles as alternative co-initiators
}

\section{Giana da Silveira LIMA(a) Andressa Goicochea MOREIRA(a) Carine Tais Welter MEEREIS ${ }^{(b)}$ Ginia Brito LIMA(c) Fernanda Barbosa LEAL ${ }^{(a)}$ Rafael Ratto de MORAES(a) Fabrício A. OGLIARI ${ }^{(d)}$ Cesar Liberato PETZHOLD(e) Evandro PIVA(a)}

\footnotetext{
(a) Universidade Federal de Pelotas UFPel, Graduate Program in Dentistry, Pelotas, RS, Brazil.

(b) Universidade Federal dos Vales do Jequitinhonha e Macuri - UFVJM, Graduate Program in Dentistry, Teófilo Otoni, MG, Brazil .

(c)|nstituto Federal do Mato Grosso - IFMT, Campo novo do Parecis, MT, Brazil.

(d) Universidade Federal de Pelotas UFPel, Materials Engineering School, Pelotas, RS, Brazil.

(e) Universidade Federal do Rio Grande do SulUFRGS, Chemistry Institute, Organic Chemistry Department, Porto Alegre, RS, Brazil.
}

Declaration of Interest: The authors certify that they have no commercial or associative interest that represents a conflict of interest in connection with the manuscript.

Corresponding Author:

Giana Silveira Lima

E-mail: gianalima@gmail.com

https://doi.org/10.1590/1807-3107bor-2018.vol32.0104

Submitted: March 16, 2018

Accepted for publication: July 24, 2018

Last revision: August 27, 2018
Abstract: This study evaluated the three-year lifespan of the bond to dentin of experimental self-etch adhesives containing benzodioxole derivatives - 1,3-benzodioxole (BDO) and piperonyl alcohol (PA) - as co-initiator alternative to amines. Adhesive resins were formulated using Bis-GMA, TEGDMA, HEMA, camphorquinone and different co-initiators: BDO, PA or ethyl 4-dimethylamino benzoate (EDAB - amine). An experimental selfetch primer was used to complete the two-step, self-etch adhesive system. Clearfil SE Bond (CSE) was used as commercial reference. Bond strength to human dentin was assessed by microtensile bond strength ( $\mu \mathrm{TBS})$ test, and failure mode was classified. Morphology of the dentin bonding interface was assessed via scanning electron microscopy (SEM). Irrespective of the dental adhesives evaluated, $\mu$ TBS was higher after 24 hours compared with that after 1.5 and 3 years $(\mathrm{p} \leq 0.001)$. However, adhesives with BDO and PA as co-initiators showed significantly higher bond strength than the bonding resin with $\operatorname{EDAB}(\mathrm{p} \leq 0.002)$, independent of the time evaluated. The commercial adhesive CSE showed similar bond strength compared with the other groups $(p \geq 0.05)$. Mixed failures were mainly observed after 24 hours, while adhesive failures were more frequently observed after 1.5 and 3 years. No notable differences in homogeneity and continuity along the bonded interfaces were detected among the materials in the SEM analysis. In conclusion, benzodioxole derivatives are feasible alternative coinitiators to tertiary amine in camphorquinone-based self-etching dental adhesive formulations.

Keywords: Adhesives; Dentin; Dental Cements; Microscopy; Dental Materials.

\section{Introduction}

The clinical success of resin composite restorations is related to durability of the bonding between the adhesive system and dental substrate. ${ }^{1,2}$ The longevity of bonding depends on the mechanical strength and hydrolytic stability of the adhesive polymer, which are modulated by the effectiveness of the polymerization reaction promoted by the photoinitiation system. ${ }^{3,4}$ The initiation system must also be biocompatible with the oral tissues. ${ }^{5}$ There is evidence that unreacted monomers may cause hydrolytic degradation of the polymer over time $\mathrm{e}^{3,6,7}$ and can be toxic, allergic, carcinogenic, or mutagenic to pulp cells., ${ }^{4,9}$ This is because 
an increase in residual monomers may affect the balance between healing and chronic inflammation of damaged dental tissues. ${ }^{10}$

The most commonly used photo-initiator system in dental polymers is based on the visible-light photosensitizer, camphorquinone (CQ). Satisfactory $\mathrm{C}=\mathrm{C}$ conversion and mechanical properties are obtained through a combination of CQ as a photosensitizer with different types of amines as co-initiators. ${ }^{4,9,11}$ However, amines are known for their toxicity and mutagenicity potentials. ${ }^{12,13}$ In addition, the conventional CQ/amine photoinitiation system tends to suffer degradation over time ${ }^{14}$ and is chemically unstable in acidic media. ${ }^{6}$ This has encouraged research efforts to identify alternative co-initiators as substitutes for amines to improve the biocompatibility of photo-initiating systems without impairing the polymerization reaction and the bonding ability of dental adhesives. ${ }^{15,16}$ Benzodioxole derivatives found in natural components have been reported to provide initiating reactivity comparable to amines, ${ }^{17,18}$ as well as to be nontoxic. ${ }^{19}$ Benzodioxoles are present in plant products included in the diets of humans and are widely available in nature. ${ }^{20}$ Furthermore, these components have been shown to have biological properties including antifungal, antibacterial, antioxidant, and antitumor activities. ${ }^{20,21,22}$

Previous studies have evaluated the use of benzodioxoles as potential co-initiators for unfilled dental resins. ${ }^{17,18,23,24}$ These components were reported as effective co-initiators for CQ-based initiator systems, leading to similar or even improved polymer properties compared with amines. ${ }^{17,18,23,24,25}$
However, the literature still lacks evidence of the dentin bonding performance of dental adhesives containing benzodioxole derivatives as co-initiators .

The aim of this study was to evaluate the influence of benzodioxole derivatives on the immediate and long-term dentin bond strength of experimental twostep, self-etch adhesives. The null hypothesis was that adhesives with the benzodioxole derivatives would have a similar bonding performance than the adhesive containing an amine co-initiator.

\section{Methodology}

\section{Materials}

Bisphenol-A glycidyl dimethacrylate (Bis-GMA), triethylene glycol dimethacrylate (TEGDMA), 2-hydroxyethyl methacrylate (HEMA) and camphorquinone (CQ) were supplied by Esstech Inc. (Essington, USA) and used without further purification. The acidic phosphate monomer HEMA-P, which is an equimolar mixture of methacryloyloxyethyl dihydrogen phosphate/ bis(methacryloyloxyethyl) hydrogen phosphate, was synthesized as previously described. ${ }^{7}$ Ethanol was obtained from Synth (Diadema, SP, Brazil). The co-initiators ethyl 4-dimethylamino benzoate (EDAB), 1,3-benzodioxole (BDO) and piperonyl alcohol (PA) were purchased from Sigma-Aldrich (Milwaukee, USA) and used as received. Figure 1 shows the structural formulas of the co-initiators evaluated.

\section{Formulation of the experimental adhesives}

An experimental self-etch primer was formulated using a mixture of $30 \mathrm{wt} \%$ HEMA-P, $30 \mathrm{wt} \%$ HEMA, $20 \mathrm{wt} \%$ distilled water, and $20 \mathrm{wt} \%$ ethanol. The

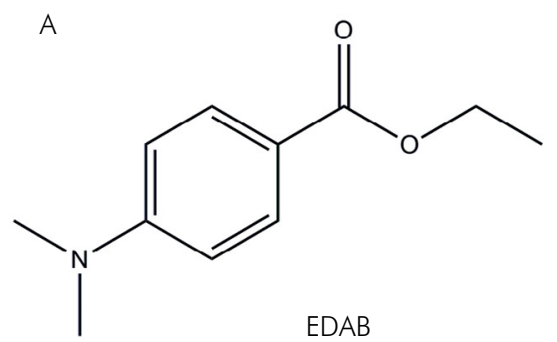

B

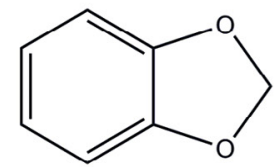

BDO
C

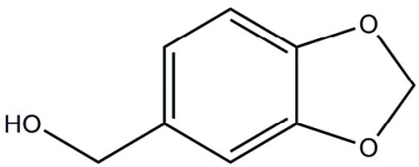

PA

Figure 1. Molecular structure of the co-initiators used in the present study. 
$\mathrm{pH}$ of the solution was measured with a digital $\mathrm{pH}$ meter (An2000; Analion, Ribeirão Preto, Brazil). An experimental adhesive resin was prepared using a mixture of $50 \mathrm{wt} \%$ Bis-GMA, $25 \mathrm{wt} \%$ TEGDMA, and $25 \mathrm{wt} \%$ HEMA. An optimal photo-initiator concentration of $1 \mathrm{~mol} \%$ CQ combined with $1 \mathrm{~mol} \%$ EDAB, $4 \mathrm{~mol} \% \mathrm{BDO}$ or $4 \mathrm{~mol} \%$ PA was established in previous studies testing the degree of $\mathrm{C}=\mathrm{C}$ conversion of the adhesives, ${ }^{33-35}$ and added to the adhesive resin. The adhesive resin of Clearfil SE Bond - CSE (Kuraray, Osaka, Japan) was tested as commercial reference. Photo-activation procedures were carried out using a halogen light curing unit (XL3000; 3M ESPE, St. Paul, USA) with $650 \mathrm{~mW} / \mathrm{cm}^{2}$ irradiance confirmed using a digital power meter (Ophir Optronics, Danvers, USA).

\section{Dentin bond strength and failure analysis}

Forty sound human third molars, removed for orthodontic reasons, were used under approval of the Research Ethics Committee (process 090/09). The teeth were cleaned and stored in a $0.5 \%$ chloramine-T solution for seven days. Ten teeth were randomly allocated to each group according to the storage time (24 hours, 1.5 years, or 3 years) or bonding resin tested (CSE, EDAB, BDO, or PA). The buccal faces were wet-ground to create a flat surface in medium dentin. To standardize the smear layer, the dentin surfaces were wet-polished with 600-grit $\mathrm{SiC}$ paper for $60 \mathrm{~s}$. Dentin moisture was controlled with absorbent paper until no surface water was observed. The dentin surfaces were vigorously etched with experimental primers for $30 \mathrm{~s}$ and air-dried for $10 \mathrm{~s}$. One coat of adhesive resin was applied and light-activated for $20 \mathrm{~s}$. Resin composite restorations (Charisma; Heraeus Kulzer, Hanau, Germany) were incrementally built-up with each increment lightactivated for $20 \mathrm{~s}$.

After storage in distilled water at $37^{\circ} \mathrm{C}$ for 24 hours, the restored teeth were sectioned perpendicularly to the bonded interfaces with a refrigerated low-speed diamond saw (ISOMET 1000 Buehler - Lake Bluff, USA) in both the mesio-distal and occluso-cervical directions. This yielded beam-shaped microtensile specimens with each cross-sectional surface area of approximately $0.7 \mathrm{~mm}^{2}$. For each tooth, 6 beams were randomly allocated into three storage times $(24 \mathrm{~h}, 1.5$ years, or 3 years). The storage media was renewed weekly during aging. ${ }^{26}$

After the predetermined storage period, the specimens were fixed into the grips of a microtensile device and tested in a mechanical testing machine (DL500; EMIC, São José dos Pinhais, Brazil) at a crosshead speed of $0.5 \mathrm{~mm} / \mathrm{min}$ until failure. Microtensile bond strength values were recorded in MPa. The data was analyzed using a two-way analysis of variance (co-initiator type vs. storage period). All pairwise multiple comparison procedures were performed using the Tukey's method $(p<0.05)$. Failure analyses for all micro-specimens tested were performed using light microscopy at $100 \times$ and 500× magnifications. The failure mode was classified as adhesive failure (interfacial), cohesive failure within resin, cohesive failure within dentin, and mixed failure, i.e., when there is more than one type of failure. Premature failures (pre-testing) were also recorded.

\section{Morphology of the dentin-bonded interfaces}

The protocol used for preparing the specimens was based on a previous study. ${ }^{27}$ Dentin discs (thickness $2 \mathrm{~mm}$ ) were obtained from the mid-coronal portion of human molars. The dentin surfaces were polished and the primer/adhesive resins were applied as previously described. Two dentin discs were bonded to each other using a thin layer of light-activated composite, generating a dentin-composite-dentin sandwich specimen. The specimens were embedded cross-sectionally in epoxy resin in order for the dentin-cement interfaces to be visible. After $24 \mathrm{~h}$, the specimens were wet-polished with 600, 1200, 1500, 2000, and 2500-grit SiC papers, followed by polishing with $3,1,0.25$ and $0.1-\mu \mathrm{m}$ diamond suspensions. The surfaces were etched with $50 \%$ phosphoric acid solution for $5 \mathrm{~s}$ and deproteinized by immersion in $2.5 \% \mathrm{NaOCl}$ solution for $10 \mathrm{~min}$. The specimens were ultrasonically cleaned in distilled water, drystored at $37^{\circ} \mathrm{C}$ for $2 \mathrm{~h}$, and coated with gold. The bonded interfaces were examined using scanning electron microscopy - SEM (SSX-550; Shimadzu, Tokyo, Japan), at $15 \mathrm{kV}$. 


\section{Results}

Table shows the results for the bond strength of the adhesives evaluated. The factors 'co-initiator type' and 'storage period' were both significant $(p \leq 0.001)$. The interaction between the two factors was not significant. The power of the performed statistical test was above 0.8 for all conditions. Irrespective of the adhesive evaluated, bond strengths at $24 \mathrm{~h}$ were significantly higher than those at 1.5 and 3 years $(p \leq 0.001)$. The adhesives with BDO and PA as co-initiators presented significantly higher bond strengths $(\mathrm{p} \leq 0.002)$ than the adhesive with EDAB as co-initiator, irrespective of the storage time. The commercial adhesive CSE showed similar bond strength compared with the BDO and PA adhesives ( $p \geq 0.05$ ).

Figure 2 shows the distribution of failure modes. For all groups, mixed failures were predominant at $24 \mathrm{~h}$ while adhesive failures were predominantly observed after 1.5 and 3 years. Pre-testing failures were also observed only after storing in water for 1.5 or 3 years. Figure 3 shows representative SEM pictures of the bonded interfaces provided by the experimental adhesives evaluated. The hybrid layer

Table. Bond strength (means (standard deviations)), in MPa, of adhesives evaluated.

\begin{tabular}{lcccc}
\hline Co-initiator & 24 hours & 1.5 years & 3 years & Pooled average \\
\hline CSE & $49.7(13.7)^{\mathrm{aAB}}$ & $26.6(5.0)^{\mathrm{bAB}}$ & $24.6(8.0)^{\mathrm{bBC}}$ & $33.5(15.3)^{\mathrm{AB}}$ \\
EDAB & $45.7(14.0)^{\mathrm{aB}}$ & $18.23(7.46)^{\mathrm{bB}}$ & $18.9(9.4)^{\mathrm{bC}}$ & $28.7(16.7)^{\mathrm{B}}$ \\
BDO & $54.5(16.64)^{\mathrm{aAB}}$ & $29.4(13.7)^{\mathrm{bAB}}$ & $32.3(10.4)^{\mathrm{bAB}}$ & $39.1(17.9)^{\mathrm{A}}$ \\
PA & $61.9(13.4)^{\mathrm{aA}}$ & $33.4(17.9)^{\mathrm{bA}}$ & $35.1(12.8)^{\mathrm{bA}}$ & $42.5(19.7)^{\mathrm{A}}$ \\
Pooled average & $53.2(15.6)^{\mathrm{a}}$ & $27.2(14.1)^{\mathrm{b}}$ & $27.8(12.0)^{\mathrm{b}}$ & - \\
\hline
\end{tabular}

Distinct uppercase (column) or lowercase (line) letters indicate significant statistical difference $(p<0.05)$.

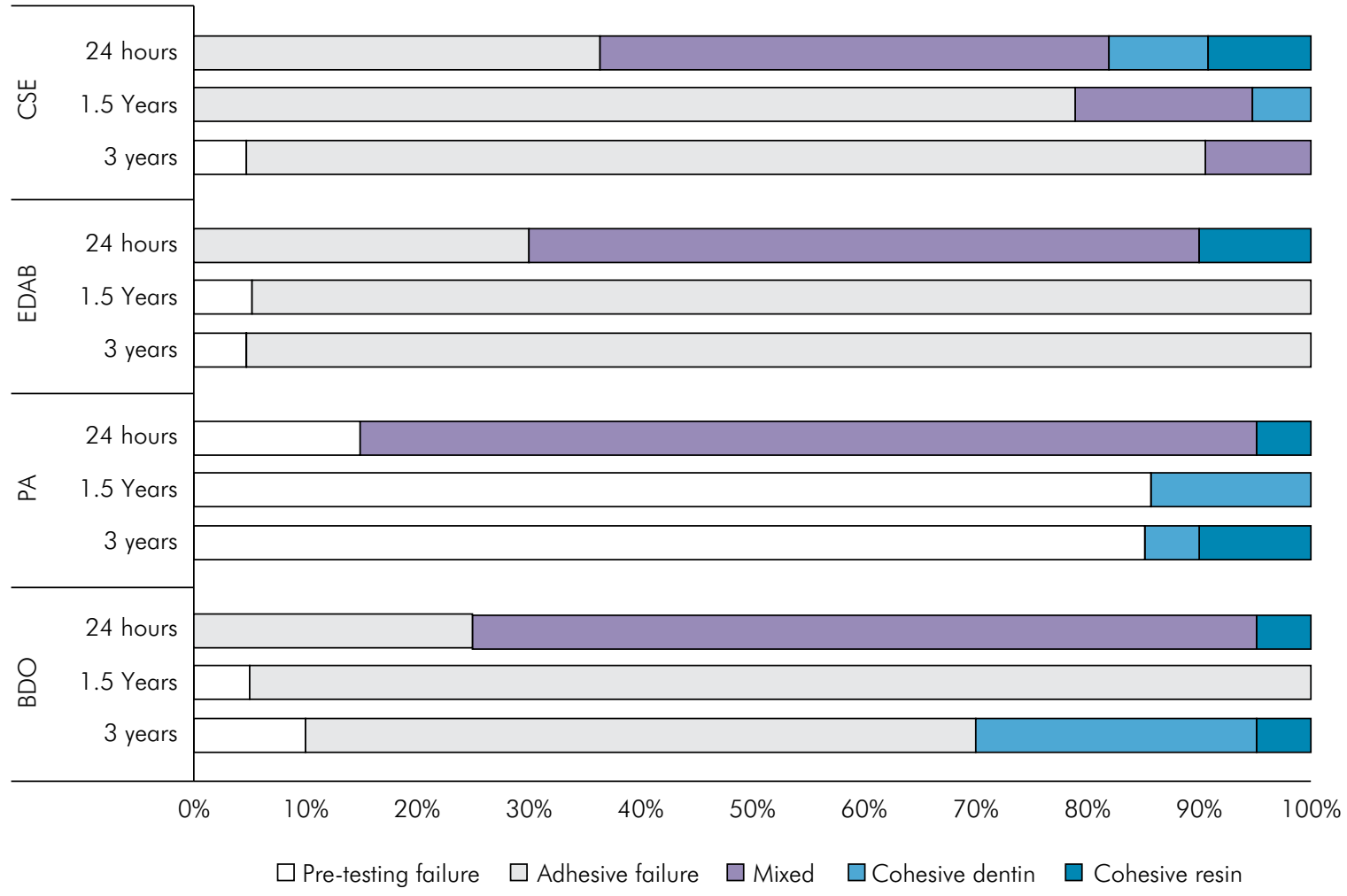

Figure 2. Distribution of failure modes for all groups (mixed failure, adhesive failure, cohesive resin, cohesive dentin). 

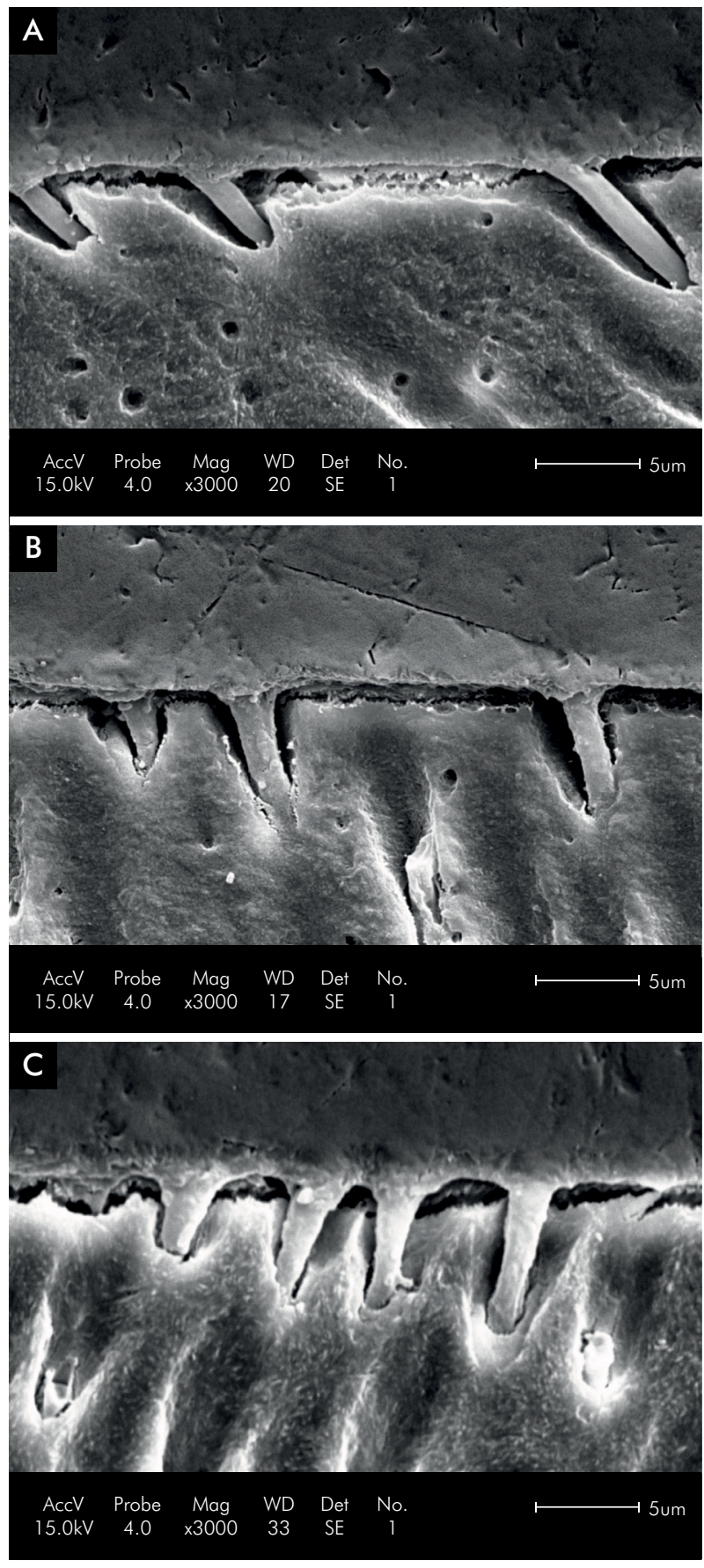

Figure 3. SEM pictures of bonded interfaces. The resin tags observed for the groups BDO and PA had a trunk-conicalshape with a rough surface similar to EDAB.

for all groups was observed to be relatively shallow (thickness $<2 \mu \mathrm{m}$ ). No appreciable differences in homogeneity and continuity of the hybrid layer along the interfaces were detected among the materials. The resin tags observed for the $\mathrm{BDO}$ and PA groups had trunk-conical shape similar to EDAB. For the group PA, the surface of the resin tags was slightly rougher compared with $\mathrm{BDO}$, with the presence of accessory hybridized tags.

\section{Discussion}

The results of this study provide evidence that benzodioxole derivatives are promising alternative co-initiators to tertiary amines in CQ-based, selfetch dental adhesive formulations. The addition of BDO or PA as co-initiators improved the dentin bond strength compared with adhesive resin with tertiary amine EDAB as co-initiator, irrespective of the storage time. Therefore, the null hypothesis was rejected.

A co-initiator is necessary for effective photopolymerization of CQ-based dental materials, ${ }^{28,29,30,31}$ because when exposed to light, CQ quickly reacts and starts the process of radical polymerization..$^{32}$ The photo-initiation reaction of binary systems involves hydrogen abstraction from the excited sensitizer to the initiator. ${ }^{30,31}$ Tertiary amines are very effective in reacting with the excited $\mathrm{CQ}^{*}$ species as an $\mathrm{H}$-donor and by oxygen scavenging reaction to generate free radicals that can start the polymerization process. ${ }^{30}$ Polymers formed using CQ/ EDAB have a high degree of $\mathrm{C}=\mathrm{C}$ conversion, ${ }^{4,6,25,28}$ which could explain the immediate bond strength being similar to that of the commercial adhesive CSE. This is because the degree of conversion is strongly related to the mechanical properties of the adhesive layer. Amines are organic nitrogen compounds derived from ammonia. They are considered basic, because they have a pair of free electrons that can bind to a cation through a dative covalent bond and are excellent proton donors. However, the amine in contact with the acidic monomer present in the self-etch adhesive system may generate an acid-base reaction, impairing the polymerization reaction and therefore the bond strength of this material over time. ${ }^{4}$ This might explain the dentin bonding performance observed for the EDAB-based adhesive during storage.

This study shows that an alternative to enhance the polymerization ${ }^{25}$ of CQ-containing self-etch 
adhesives and their dentin bond strength is the use of benzodioxole derivatives. The use of these natural components may also decrease the cytotoxicity and improve the biocompatibility of dental biomaterials, ${ }^{19}$ especially those placed in deep cavities. The free-radical formation mechanism of PA and BDO in CQ-based materials involves hydrogen abstraction through cyclic acetyl radicals generated by the photo-irradiation onto cyclic acetyl compounds. This might be rearranged rapidly by B-scission to the corresponding ester radicals. ${ }^{25}$ For PA, the hydrogen abstraction from the methylenebridge carbon could also occur to form a methylene dioxybenzene radical and initiate polymerization with the methacrylate monomers. ${ }^{18,25} \mathrm{PA}$ showed improved immediate bond strength compared with CQ/EDAB and similar bond strength to the other groups tested.

The similar molecular structure of the two benzodioxole derivatives tested herein could explain the similar behavior of adhesive systems containing BDO or PA. The dentin hybridization observed for these two materials suggests good interaction with the dentin substrate. However, the SEM analysis suggested a better interaction of PA with dentin. This finding might be related to the higher hydrophilicity of PA due to the presence of the methanol group. The hydrophilicity increases the solubility of the adhesive resin with co-initiator and facilitates hybridization to dentin, which is a naturally moist substrate. ${ }^{33}$ To achieve optimal dentin bond strength, the adhesive needs to hybridize with the intertubular and peritubular dentin, since the actual contribution of hybridized resins tags to bond strengths is not sufficiently explained. ${ }^{34} \mathrm{EDAB}$ showed more adhesive failures than the alternatives co-initiators. It is hypothesized that the acid-base reaction between the amine and self-etch monomers led to lower $\mathrm{C}=\mathrm{C}$ conversion. ${ }^{4}$

Irrespective of the co-initiator tested, all adhesives showed a reduction in bond strength values after 1.5 and 3 years of storage in water. This reduction may be associated with the degradation of the hybrid layer due to hydrolytic phenomena. The polymer absorbs water which triggers a relaxation of polymer chains, causing a reduction in bond strength. ${ }^{35}$ In addition, the ester group of the methacrylate monomers undergoes hydrolysis when the medium is aqueous and acidic, as for example in self-etching adhesive systems. ${ }^{36}$ Another factor accounting for the decrease of the bond strength is the extracellular matrix metalloproteinases (MMPs). These enzymes have been associated with the degradation of the collagen, which forms the hybrid layer. They are endogenous enzymes that are released from the matrix and activated. The inhibition of these enzymes by the host is of great importance to the longevity of adhesive restorations. ${ }^{37,38}$

Bond strength tests are limited in terms of extrapolation of data for clinical performance. These tests help to select between different compositions of material. Among the bond strength tests, the microtensile test has a uniform distribution of stresses and has the ability to correlate with clinical retention data. Storage of specimens in water should be performed to evaluate possible degradation of the material. The microtensile test can be used to evaluate the bond strength in clinically critical areas, such as the cervical Class II restorations. This critical area can be adopted as a reference to improve the composition and hence the effectiveness of the adhesive systems. ${ }^{39}$

The literature points out the need for further studies on water-compatible photo-initiator systems. ${ }^{40}$ The use of BDO and PA promoted better adhesion to the substrate even over time, making them viable alternatives. These co-initiators exhibit watercompatible characteristics, which are desirable to overcome the challenges associated with moist environments. Furthermore, they may present the advantage of reduced toxicity during manufacture, as well as reduced production of toxic waste. These can be considered potential clinical and environmental implications related to the use of the alternative co-initiators tested here. However, one should keep in mind that these findings are still restricted to the in vitro performance of the molecules tested and further evaluation is required for a better assessment of the feasibility of using these components in actual dental adhesive systems. 


\section{Conclusion}

This study shows that benzodioxole derivatives can be used as an alternative to the conventional tertiary amine co-initiators in CQ-based, self-etch dental adhesive formulations. After prolonged storage, adhesives with 1,3-benzodioxole or piperonyl alcohol showed higher dentin bond strengths than ethyl 4-dimethylamino benzoatecontaining adhesives.

\section{References}

1. Rodolpho PAR, Donassollo TA, Cenci MS, Loguércio AD, Moraes RR, Bronkhorst EM et al. 22-Year clinical evaluation of the performance of two posterior composites with different filler characteristics. Dent Mater. 2011 Oct;27(10):955-63. https://doi.org/10.1016/i.dental.2011.06.001

2. Opdam NJ, Bronkhorst EM, Loomans BA, Huysmans MC. 12-year survival of composite vs. amalgam restorations. J Dent Res. 2010 Oct;89(10):1063-7. https://doi.org/10.1177/0022034510376071

3. Leal FB, Lima GS, Collares FM, Samuel SM, Petzhold CL, Piva $\mathrm{E}$ et al. lodonium salt improves the dentin bonding performance in an experimental dental adhesive resin. Int J Adhes Adhes. 2012;38:1-4. https://doi.org/10.1016/j.ijadhadh.2012.05.008

4. Meereis CT, Leal FB, Lima GS, Carvalho RV, Piva E, Ogliari FA. BAPO as an alternative photoinitiator for the radical polymerization of dental resins. Dent Mater. 2014 Sep;30(9):94553. https://doi.org/10.1016/i.dental.2014.05.020

5. Nakabayashi N, Kojima K, Masuhara E. The promotion of adhesion by the infiltration of monomers into tooth substrates. J Biomed Mater Res. 1982 May;16(3):265-73. https://doi.org/10.1002/jbm.820160307

6. Meereis CT, Leal FB, Ogliari FA. Stability of initiation systems in acidic photopolymerizable dental material. Dent Mater. 2016 Jul;32(7):889-98. https://doi.org/10.1016/j.dental.2016.03.016

7. Leal FB, Madruga FC, Prochnow EP, Lima GS, Ogliari FA, Piva E et al. Effect of acidic monomer concentration on the dentin bond stability of self-etch adhesives. Int J Adhes Adhes. 2011;31(6):5714. https://doi.org/10.1016/i.jiadhadh.2011.05.007

8. Cooper PR, Takahashi Y, Graham LW, Simon S, Imazato $\mathrm{S}$, Smith AJ. Inflammation-regeneration interplay in the dentine-pulp complex. J Dent. 2010 Sep;38(9):687-97. https://doi.org/10.1016/j.jdent.2010.05.016

9. Jakubiak J, Allonas X, Fouassier J, Sionkowska A, Andrzejewska $E$, Linden LÅ et al. Camphorquinone-amines photoinitating systems for the initiation of free radical

\section{Acknowledgments}

The authors are grateful to $\mathrm{CNPq} /$ Brazil for providing a junior postdoctoral scholarship (159712/2011-4) and financial support (grants 479058/2009-1). The authors also thank the Biomaterials Development and Control Center CDCBio-UFPel and Dr. Tatiana Ramos for technical support.

polymerization. Polymer (Guildf). 2003;44(18):5219】26. https://doi.org/10.1016/S0032-3861(03)00568-8

10. Leprince JG, Zeitlin BD, Tolar M, Peters OA. Interactions between immune system and mesenchymal stem cells in dental pulp and periapical tissues. Int Endod J. 2012 Aug;45(8):689701. https://doi.org/10.1111/j.1365-2591.2012.02028.x

11. Schroeder WF, Cook WD, Vallo Cl. Photopolymerization of N, $\mathrm{N}$-dimethylaminobenzyl alcohol as amine co-initiator for lightcured dental resins. Dent Mater. 2008 May;24(5):686-93. https://doi.org/10.1016/j.dental.2007.06.035

12. Cramer NB, Stansbury JW, Bowman CN. Recent advances and developments in composite dental restorative materials. J Dent Res. 2011 Apr;90(4):402-16. https://doi.org/10.1177/0022034510381263

13. Weisburger EK, Russfield AB, Homburger F, Weisburger JH, Boger E, Van Dongen $C G$ et al. Testing of twenty-one environmental aromatic amines or derivatives for long-term toxicity or carcinogenicity. J Environ Pathol Toxicol. 1978 Nov-Dec;2(2):325-56.

14. Albuquerque PP, Moreira AD, Moraes RR, Cavalcante LM, Schneider LF. Color stability, conversion, water sorption and solubility of dental composites formulated with different photoinitiator systems. J Dent. 2013 Aug;41 Suppl 3:e67-72. https://doi.org/10.1016/i.jdent.2012.11.020

15. Park YJ, Chae KH, Rawls HR. Development of a new photoinitiation system for dental light-cure composite resins. Dent Mater. 1999 Mar;15(2):120-7. https://doi.org/10.1016/S0109-5641(99)00021-4

16. Wang K, Yang D, Xiao M, Chen X, Lu F, Nie J. Sesamin as a co-initiator for unfilled dental restorations. Acta Biomater. 2009 Sep;5(7):2508-17. https://doi.org/10.1016/i.actbio.2009.03.008

17. Shi S, Nie J. A natural component as coinitiator for unfilled dental resin composites. J Biomed Mater Res B Appl Biomater. 2007 Jul;82(1):44-50. https://doi.org/10.1002/jbm.b.30703 
18. Liu S, Shi S, Hou G, Nie J. Benzodioxole derivative as coinitiator for dental resin. Acta Odontol Scand. 2007 Nov;65(6):313-8. https://doi.org/10.1080/00016350701742349

19. Micale N, Zappalà $M$, Grasso S. Synthesis and antitumor activity of 1,3-benzodioxole derivatives. Farmaco. 2002 Oct;57(10):8539. https://doi.org/10.1016/S0014-827X(02)01276-4

20. Hickey MJ. Investigation of the chemical constituents of Brazilian sassafras oil. J Org Chem. 1948 May;13(3):443-6. https://doi.org/10.1021/jo01161a020

21. Regnier G, Canevari R, Laubie M, Poignant J-C, inventors. Science Union \& Cie, assignee. Benzodioxole compounds. United States Patents US. 1973 Mar 16.

22. Micale N, Zappalà M, Grasso S. Synthesis and cytotoxic activity of 1,3-benzodioxole derivatives. Note II. Farmaco. 2003 May;58(5):351-5. https://doi.org/10.1016/S0014-827X(03)00053-3

23. Shi $S$, Gao H, Wu G, Nie J. Cyclic acetal as coinitiator for bimolecular photoinitiating systems. Polymer (Guildf). 2007;48(10):2860-5. https://doi.org/10.1016/i.polymer.2007.03.027

24. Shi S, Xiao P, Wang K, Gong Y, Nie J. Influence of chemical structures of benzodioxole-based coinitiators on the properties of the unfilled dental resin. Acta Biomater. 2010 Aug;6(8):3067-71. https://doi.org/10.1016/i.actbio.2010.02.022

25. Lima GS, Ogliari FA, Silva MGS, Münchow EA, Petzhold CL, Piva E. Benzodioxoles as alternative coinitiators for radical polymerization in a model-dental adhesive resin. J Appl Polym Sci. 2013;127(5):4160-7. https://doi.org/10.1002/app.38020

26. Van Meerbeek B, Peumans M, Poitevin A, Mine A, Van Ende A, Neves A et al. Relationship between bond-strength tests and clinical outcomes. Dent Mater. 2010 Feb;26(2):e100-21. https://doi.org/10.1016/i.dental.2009.11.148

27. Lima GS, Ogliari FA, Silva EO, Ely C, Demarco FF, Carreño $\mathrm{NL}$ et al. Influence of water concentration in an experimental self-etching primer on the bond strength to dentin. J Adhes Dent. 2008 Jun;10(3):167-72.

28. Ogliari FA, Ely C, Petzhold CL, Demarco FF, Piva E. Onium salt improves the polymerization kinetics in an experimental dental adhesive resin. J Dent. 2007 Jul;35(7):583-7. https://doi.org/10.1016/j.jdent.2007.04.001

29. Moon HJ, Shin DH. Effect of CQ-amine ratio on the degree of conversion in resin monomers with binary and ternary photoinitiation systems. Restor Dent Endod. 2012;37(2):96102. https://doi.org/10.5395/rde.2012.37.2.96
30. Andrzejewska E. Photopolymerization kinetics of multifunctional monomers. Prog Polym Sci. 2001;26(4):60565. https://doi.org/10.1016/S0079-6700(01)00004-1

31. Yamasaki LC, De Vito Moraes AG, Barros M, Lewis S, Francci C, Stansbury JW et al. Polymerization development of "lowshrink" resin composites: reaction kinetics, polymerization stress and quality of network. Dent Mater. 2013 Sep;29(9):e169-79. https://doi.org/10.1016/i.dental.2013.04.021

32. Chen Y-C, Ferracane JL, Prahl SA. Quantum yield of conversion of the photoinitiator camphorquinone. Dent Mater. 2007;23(6):655-64. https://doi.org/10.1016/i.dental.2006.06.005

33. Van Landuyt KL, Yoshida Y, Hirata I, Snauwaert J, De Munck J, Okazaki M et al. Influence of the chemical structure of functional monomers on their adhesive performance. J Dent Res. 2008 Aug;87(8):757-61. https://doi.org/10.1177/154405910808700804

34. Prati C, Chersoni S, Mongiorgi R, Pashley DH. Resin-infiltrated dentin layer formation of new bonding systems. Oper Dent. 1998 Jul-Aug;23(4):185-94.

35. Brazel CS, Peppas NA. Mechanisms of solute and drug transport in relaxing, swellable, hydrophilic glassy polymers. Polymer (Guildf). 1999;40(12):3383-98. https://doi.org/10.1016/S0032-3861(98)00546-1

36. Nishiyama N, Suzuki K, Yoshida H, Teshima H, Nemoto K. Hydrolytic stability of methacrylamide in acidic aqueous solution. Biomaterials. 2004 Mar;25(6):965-9. https://doi.org/10.1016/S0142-9612(03)00616-1

37. Pashley DH, Tay FR, Breschi L, Tjäderhane L, Carvalho RM, Carrilho $M$ et al. State of the art etch-andrinse adhesives. Dent Mater. 2011 Jan;27(1):1-16. https://doi.org/10.1016/j.dental.2010.10.016

38. Pashley DH, Tay FR, Yiu C, Hashimoto M, Breschi L, Carvalho RM et al. Collagen degradation by host-derived enzymes during aging. J Dent Res. 2004 Mar;83(3):216-21. https://doi.org/10.1177/154405910408300306

39. Heintze SD. Clinical relevance of tests on bond strength, microleakage and marginal adaptation. Dent Mater. 2013 Jan;29(1):59-84. https://doi.org/10.1016/j.dental.2012.07.158

40. Wang $Y$, Spencer $P, Y a o X, Y e$ Q. Effect of coinitiator and water on the photoreactivity and photopolymerization of HEMA/camphoquinone-based reactant mixtures. J Biomed Mater Res A. 2006 Sep;78(4):721-8. https://doi.org/10.1002/ibm.a.30733 